SMOKING

\title{
Childhood smoking is an independent risk factor for obstructive airways disease in women
}

\author{
B D Patel, R N Luben, A A Welch, S A Bingham, K-T Khaw, N E Day, D A Lomas, N J Wareham
}

Thorax 2004;59:682-686. doi: 10.1136/thx.2003.010215

See end of article for authors' affiliations

.......................

Correspondence to: Dr B Patel, Department of Public Health and Primary Care, Institute of Public Health, University Forvie Site, Robinson Way, Cambridge CB2 2SR, UK bip@srl.cam.ac.uk

Received 12 May 2003 Accepted 8 April 2004
Objective: To assess whether starting to smoke in childhood increases the risk of obstructive airways disease (OAD) in adult life.

Methods: A retrospective cohort analysis was undertaken of 12504 current and ex-smokers in the EPICNorfolk cohort. The main exposure was starting to smoke during childhood (age <16 years). Three definitions of OAD were used: doctor diagnosed asthma, doctor diagnosed bronchitis/emphysema, and "any $O A D^{\prime}$ (doctor diagnosed asthma or bronchitis/emphysema, or taking medication used in the treatment of OAD).

Results: Childhood smokers had significantly more pack years of exposure and poorer lung function than subjects who started to smoke in adulthood ( $\geqslant 16$ years). Compared with starting in adulthood, starting to smoke in childhood was associated with a greater risk of bronchitis/emphysema in female smokers (OR $1.79,95 \% \mathrm{Cl} 1.25$ to 2.56 ) and ex-smokers of both sexes (OR $1.29,95 \% \mathrm{Cl} 1.07$ to 1.55 in men and OR $1.40,95 \% \mathrm{Cl} 1.05$ to 1.85 in women), and of "any OAD" in female smokers (OR $1.72,95 \% \mathrm{Cl} 1.24$ to 2.38 ) and male and female ex-smokers (OR $1.20,95 \% \mathrm{Cl} 1.03$ to 1.40 in men and $1.34,95 \% \mathrm{Cl} 1.07$ to 1.57 in women). After adjustment for pack years, childhood smoking was associated with poorer lung function ( $\mathrm{FEV}_{1} 92.3 \%$ predicted in adult smokers and $89.5 \%$ in childhood smokers, $p=0.03$ ) and a greater risk of bronchitis/emphysema (adjusted OR $1.55,95 \% \mathrm{Cl} 1.08$ to 2.24 ) and for "any OAD" (OR 1.54, $95 \% \mathrm{Cl} 1.10$ to 2.13 ) in female smokers but not in male and female ex-smokers.

Conclusion: Starting to smoke in childhood is associated with an increased risk of airways disease because of the extra pack years smoked. In women, childhood smoking is itself an independent risk factor for the development of airways disease.
$\mathrm{O}$ ver the past 25 years the prevalence of smoking has remained stable in English children aged 11-15 years at a time when smoking rates have fallen in adults. Similar trends have been reported in other European countries and the USA, and in all cases the prevalence of smoking in young girls is equal to or greater than that in boys. ${ }^{2-4}$ Although cigarette smoking is the major environmental risk factor for the development of chronic obstructive pulmonary disease (COPD), only about $15 \%$ of smokers develop significant airflow obstruction. The development of COPD in a minority of smokers has been attributed to a greatly accelerated rate of decline of forced expiratory volume in 1 second $\left(\mathrm{FEV}_{1}\right)$ in "susceptible smokers". ${ }^{5}{ }^{6}$ Even without this additional susceptibility, smokers who enter adult life with a low $\mathrm{FEV}_{1}$ may be at risk of developing airflow obstruction as a result of the modestly increased rate of decline in $\mathrm{FEV}_{1}$ observed in the majority of smokers. ${ }^{7}$

A substantial proportion of adult smokers start to smoke in childhood ${ }^{8-10}$ Childhood smokers are more likely to continue smoking than individuals who start smoking in later life, ${ }^{11-13}$ and therefore may be expected to have a greater risk of developing COPD as a result of their greater cumulative tobacco consumption. It has been shown that children who smoke experience more respiratory symptoms and have poorer lung function than their non-smoking peers. ${ }^{14-18}$ However, it is not clear whether the reduced lung growth experienced by childhood smokers ${ }^{15}$ is an independent risk factor for the development of obstructive airways disease in later life. We addressed these questions using data from the Norfolk arm of the European Prospective Investigation of Cancer (EPIC-Norfolk). In a retrospective analysis we assessed the independent effects of childhood smoking and cumulative tobacco consumption on the risk of airways disease in adult life.

\section{METHODS}

The EPIC-Norfolk cohort is a population based cohort of men and women aged 45-75 years. The primary objective of the EPIC-Norfolk cohort is to prospectively assess the association of diet and other lifestyle exposures with the development of chronic disease. The individuals in the study were recruited from 35 general practices in and around the city of Norwich. A detailed description of the recruitment, operation and characteristics of the cohort is published elsewhere. ${ }^{19}$ Between 1993 and 1998, 24842 people (13 444 of whom were current or ex-smokers) attended for a health check at which anthropometric measurements were made and spirometric tests performed. Spirometric tests were conducted by a nurse trained in the technique using a hand held electronic turbine spirometer (Micro Medical Instruments, Rochester, UK). Two standing measurements were made and the higher of the two values of $\mathrm{FEV}_{1}$ was used.

Smoking status was obtained from a health and lifestyle questionnaire by the response to the question: "Have you ever smoked as much as one cigarette per day for a year?" Current smokers were identified by a positive response to the question: "Do you smoke cigarettes now?" Individuals who responded positively to the first question but negatively to the second question were classified as ex-smokers. Pack years smoked were calculated from the reported age of starting, age of quitting, and the number of cigarettes smoked at age 20, $30,40,50$ and at the time of the study. The algorithm used to calculate total pack years took into account periods of abstinence. The average number smoked per day was 
Table 1 Characteristics of current and ex-smokers by sex and age of starting to smoke

\begin{tabular}{|c|c|c|c|c|c|c|c|c|}
\hline & \multicolumn{2}{|c|}{ Male smokers $(n=1294)$} & \multicolumn{2}{|c|}{ Male ex-smokers $(n=5792)$} & \multicolumn{2}{|c|}{ Female smokers $(n=1416)$} & \multicolumn{2}{|c|}{ Female ex-smokers $(n=4002)$} \\
\hline & Childhood & Adulthood & Childhood & Adulthood & Childhood & Adulthood & Childhood & Adulthood \\
\hline Percentage (n) & $37.2(481)$ & $62.8(813)$ & $27.2(1575)$ & $72.8(4217)$ & $16.2(230)$ & $83.8(1186)$ & $12.0(481)$ & 88.0 (3521) \\
\hline Age (years) & $56.8(8.9)$ & $57.6(8.9)$ & $60.4 \ddagger(9.2)$ & $61.5 \ddagger(9.2)$ & $53.7 \ddagger(8.1)$ & $56.7 \ddagger(8.7)$ & $56.2 \ddagger(9.4)$ & $60.1 \mp(9.6)$ \\
\hline $\begin{array}{l}\text { Age started } \\
\text { smoking (years) }\end{array}$ & $13.9 \ddagger(1.6)$ & $18.4 \ddagger(4.0)$ & $14.1 \neq(1.3)$ & $18.3 \ddagger(3.2)$ & $14.4 \ddagger(1.1)$ & $20.5 \ddagger(6.1)$ & $14.4 \ddagger(1.0)$ & $20.0 \mp(5.2)$ \\
\hline Cigareftes per day & $19.2 \pm(7.1)$ & $16.3 \ddagger(7.1)$ & $20.3 \ddagger(9.9)$ & $15.9 \ddagger(9.2)$ & $15.5 \ddagger(5.9)$ & $13.2 \pm(5.9)$ & $15.6 \neq(8.0)$ & $10.8 \mp(7.3)$ \\
\hline Years of smoking & $42.9 \neq(9.2)$ & $39.2 \ddagger(9.4)$ & $23.9 \ddagger(15.8)$ & $19.2 \ddagger(14.2)$ & $39.3 \ddagger(8.3)$ & $36.2 \ddagger(9.6)$ & $23.3 \ddagger(14.6)$ & $18.2 \ddagger(13.3)$ \\
\hline Pack years & $38.1 \mp(17.8)$ & $29.2 \ddagger(15.9)$ & $26.1 \mp(20.3)$ & $16.6 \neq(16.1)$ & $28.0 \neq(13.2)$ & $22.7 \ddagger(13.3)$ & $19.6 \neq(15.2)$ & $11.3 \ddagger(12.2)$ \\
\hline Asthma, \% (n) & $5.4(26)$ & $6.8(55)$ & 8.8 (138) & $7.9(334)$ & $11.3^{*}(26)$ & $7.3^{*}(86)$ & $12.7(61)$ & $10.3(362)$ \\
\hline Bronchitis/ & $11.5(55)$ & $10.5(85)$ & $11.6+(182)$ & $9.2+(389)$ & $21.3 \ddagger(49)$ & $13.2 \ddagger(156)$ & $14.0 *(67)$ & $10.4^{*}(366)$ \\
\hline emphysema, \% (n) & & & $179 *(28)$ & $153 * 16441$ & $278+(64)$ & $183+12171$ & & $186+16531$ \\
\hline & & & & & & & & \\
\hline \multicolumn{9}{|c|}{$\begin{array}{l}\text { Figures are mean }(S D) \text { or } \%(n) \text {. } \\
\text { Cigarettes per day = the mean number of cigarettes smoked per day while an active smoker. } \\
\text { "Any } O A D \text { " is defined as the presence of doctor diagnosed asthma or doctor diagnosed bronchitis/emphysema, or self- reported taking of medication for airway } \\
\text { disease. } \\
\text { " } p<0.05, \mathrm{p} \leqslant 0.01, \neq p \leqslant 0.001 \text { for the difference within smoking categories between those who started to smoke in childhood (age }<16 \text { years) and those wh } \\
\text { started in adulthood (age } \geqslant 16 \text { years). }\end{array}$} \\
\hline
\end{tabular}

calculated as the mean of the number smoked per day for each decade that the individual was a smoker. The duration of smoking was calculated as the difference between the age of starting and age of quitting (ex-smokers), or the age of starting and age at survey (current smokers). Social class was determined according to the Registrar General's classification of occupations.

The presence of obstructive airways disease (OAD) was determined by self-reported doctor diagnosed asthma or bronchitis/emphysema in the health and lifestyle questionnaire. It was also deduced from the self-reported taking of medication used in the treatment of OAD at the time of the health check (inhaled steroids or bronchodilators, oral methylxanthines, or leukotriene antagonists). In the analysis three definitions of OAD were used: physician diagnosed asthma, physician diagnosed bronchitis/emphysema, and "any OAD" (which included people who reported either a diagnosis of asthma or bronchitis/emphysema or who reported taking medications used for the treatment of OAD). We included the category "any OAD" because of the lack of specificity and potential overlap of the diagnosis of asthma with chronic bronchitis/emphysema in smokers. In this study we refer to people who reported starting to smoke under the age of 16 as "childhood smokers" and those who started at age 16 or over as having started in adulthood.

The study was approved by the Norfolk local research ethics committee.

\section{Statistical analysis}

Cox regression analysis was used to assess the effects of starting to smoke in childhood on the subsequent risk of

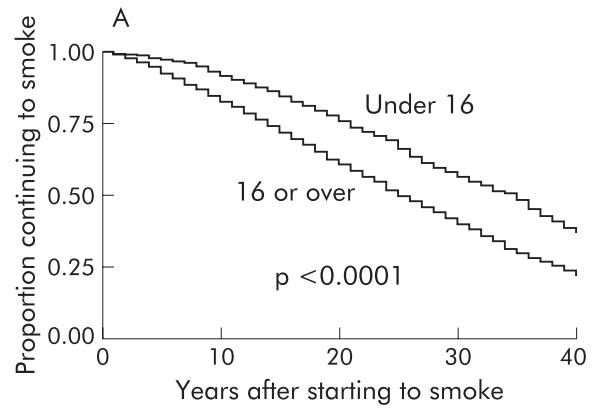

quitting. The association between childhood smoking and airways disease was assessed independently in men and women stratified by smoking status (current and exsmokers) using two methods. Firstly, for each of the three definitions of $\mathrm{OAD}$ we estimated the stratum specific risk ratio for childhood smokers relative to those who started in adulthood. Secondly, we assessed the effect of childhood smoking on $\mathrm{FEV}_{1}$ percent predicted. Predicted values of $\mathrm{FEV}_{1}$ were calculated independently for each sex using regression coefficients derived for height and age on $\mathrm{FEV}_{1}$ in 3238 men and 6467 women in the EPIC-Norfolk cohort who were lifelong non-smokers without OAD. Differences in proportions were compared using a $\chi^{2}$ test. For continuous variables the differences in means between groups were compared using the Student's $t$ test, Kruskal-Wallis test, or analysis of variance (ANOVA) as appropriate. Multiple logistic regression models were used to estimate odds ratios with potential confounding variables included as covariates. Effect modification of the association by sex was assessed in pooled analyses of men and women by the inclusion of an interaction term between sex and childhood smoking.

\section{RESULTS}

The age at which subjects first started to smoke was available for 12504 (93\%) current and ex-smokers who performed spirometric tests (table 1). More than twice as many men than women reported starting to smoke in childhood $(37.2 \%$ male smokers $v 16.2 \%$ female smokers, $\mathrm{p} \leqslant 0.001 ; 27.2 \%$ male ex-smokers $v 12.0 \%$ female ex-smokers, $p \leqslant 0.001)$. In all cases childhood smokers had significantly more cumulative pack years of exposure due to a combination of heavier

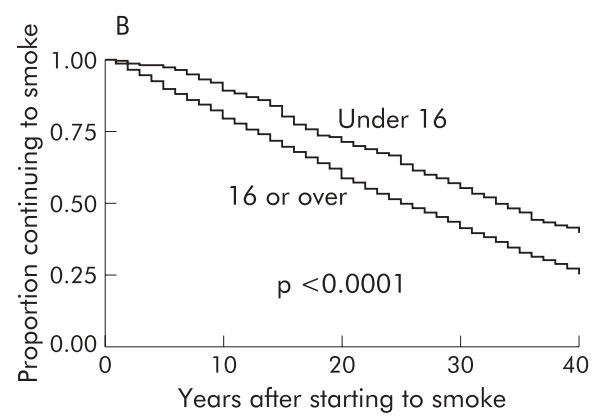

Figure 1 Kaplan-Meier plots of the proportion of (A) men and (B) women who continued to smoke during the 40 year period after first starting to smoke, by age at which they started smoking. 
Table 2 Association between tobacco consumption and risk of physician diagnosed airways disease

\begin{tabular}{|c|c|c|c|c|c|c|}
\hline \multirow[b]{3}{*}{ Smoking exposure } & \multirow{2}{*}{\multicolumn{2}{|c|}{$\begin{array}{l}\text { Asthma } \\
\text { OR }(95 \% \mathrm{Cl})\end{array}$}} & \multirow{2}{*}{\multicolumn{2}{|c|}{$\begin{array}{l}\text { Bronchitis/emphysema } \\
\text { OR }(95 \% \mathrm{Cl})\end{array}$}} & \multirow{2}{*}{\multicolumn{2}{|c|}{$\begin{array}{l}\text { "Any OAD" } \\
\text { OR }(95 \% \mathrm{Cl})\end{array}$}} \\
\hline & & & & & & \\
\hline & Unadjusted & Adjusted & Unadjusted & Adjusted & Unadjusted & Adjusted \\
\hline $\begin{array}{l}\text { Per } 10 \text { cigarettes/ } \\
\text { day }\end{array}$ & 1.02 (0.95 to 1.09 ) & $0.96(0.85$ to 1.08$)$ & $1.20^{*}(1.13$ to 1.28$)$ & $1.00(0.90$ to 1.11$)$ & $1.12^{*}(1.07$ to 1.18$)$ & $0.96(0.88$ to 1.05$)$ \\
\hline $\begin{array}{l}\text { Per } 10 \text { years of } \\
\text { smoking }\end{array}$ & 1.00 (0.96 to 1.04$)$ & $0.97(0.91$ to 1.03$)$ & $1.15^{*}(1.11$ to 1.20$)$ & $1.06(1.00$ to 1.11$)$ & $1.08 *(1.05$ to 1.11$)$ & $1.00(0.96$ to 1.05$)$ \\
\hline $\begin{array}{l}\text { Per } 10 \text { pack years } \\
\text { smoked }\end{array}$ & 1.01 (0.98 to 1.05 ) & 1.05 (0.98 to 1.13 ) & $1.16^{*}(1.13$ to 1.20$)$ & $1.14^{*}(1.07$ to 1.21$)$ & $1.10^{*}(1.07$ to 1.13$)$ & $1.12^{*}(1.07$ to 1.19$)$ \\
\hline
\end{tabular}

smoking (more cigarettes consumed a day) and a greater duration of smoking. The proportion of ever smokers who subsequently quit was greater in men than in women $(81.3 \%$ $v 73.8 \%, \mathrm{p} \leqslant 0.001$ ) but, within each sex, childhood smokers were less likely to quit (fig 1). The hazard ratio (HR) for quitting in those who started smoking in adulthood relative to childhood smokers was 1.54 (CI 1.44 to $1.63, \mathrm{p} \leqslant 0.001$ ) in men and 1.49 (CI 1.31 to $1.59, \mathrm{p} \leqslant 0.001$ ) in women. The likelihood of quitting showed a significant trend across social class in both sexes with those in social class 5 being less likely to quit smoking $(p \leqslant 0.001$, test for trend within each $\operatorname{sex}$ ). However, after adjusting for social class in multivariate analysis, starting to smoke in adulthood remained associated with a significantly increased likelihood of quitting (adjusted HR 1.48 , CI 1.38 to $1.57, \mathrm{p} \leqslant 0.001$ in men and 1.40 , CI 1.26 to $1.55, \mathrm{p} \leqslant 0.001$ in women relative to childhood smokers).

The overall prevalence of asthma, bronchitis/emphysema, and "any OAD" in the study population was $8.7 \%, 10.8 \%$, and $17.4 \%$, respectively. Asthma was more common in exsmokers than in current smokers $(9.2 \% \vee 7.1 \%, \mathrm{p}=0.001)$. Although this suggests a possible healthy smoker effect, chronic bronchitis/emphysema was more common in current smokers than in ex-smokers $(12.7 \% v 10.3 \%, \mathrm{p}<0.001)$ and there was no significant difference between the prevalence of "any OAD" (17.7\% current smokers and 17.3\% ex-smokers).

Table 2 shows the association between smoking and OAD. In univariate analyses, the mean number of cigarette smoked per day, duration of smoking, and cumulative pack years smoked were all associated with the risk of bronchitis/ emphysema and "any OAD". However, after mutual adjustment, only pack years remained significantly associated with the risk of either disease (table 2). In women who continued to smoke the prevalence of asthma, bronchitis/emphysema, and "any OAD" was greater in childhood smokers, with approximately one in four of these women fulfilling the

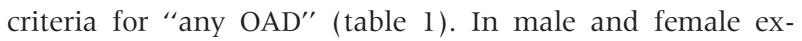
smokers, childhood smokers had a significantly greater prevalence of bronchitis/emphysema and "any OAD" than those who started smoking in adulthood. Starting to smoke in childhood was associated with a significantly greater cumulative pack year exposure that may account for the increased risk of airways disease.

Multiple logistic regression models were used to adjust for the effects of cumulative pack years smoked and social class on respiratory disease. In these models social class was not a significant covariate and so was excluded from the analysis. The results of these analyses are summarised in table 3 . After adjusting for total pack years smoked, the excess risk for chronic bronchitis/emphysema and "any OAD" associated with smoking in childhood was no longer significant in male and female ex-smokers. Thus, in these individuals the increased risk of OAD associated with smoking in childhood is explained by the extra pack years smoked. In women who continued to smoke, starting to smoke in childhood remained an independent risk factor for the development of bronchitis/ emphysema and "any OAD", even after adjustment for the extra pack years of smoking. Additional adjustment for number of cigarettes smoked per day and years of smoking did not affect the association with childhood smoking in these women. Moreover, neither exposure was significant as a covariate after adjustment for pack years.

In pooled analyses of male and female current smokers there was a significant interaction between sex and childhood smoking in the model for bronchitis/emphysema $(p=0.03)$ and the model for "any OAD" $(p=0.03)$.

Percentage predicted $\mathrm{FEV}_{\mathrm{l}}$ was lower in subjects who started to smoke in childhood than in those who started to smoke in adulthood, although the difference was not statistically significant in female ex-smokers (fig 2). After adjusting for pack years smoked there was no significant

Table 3 Odds ratios for the presence of airways disease in childhood smokers by sex and smoking status

\begin{tabular}{|c|c|c|c|c|c|}
\hline \multirow[b]{2}{*}{ Disease } & \multirow[b]{2}{*}{ Model } & \multicolumn{2}{|l|}{ Men } & \multicolumn{2}{|l|}{ Women } \\
\hline & & Smokers & Ex-smokers & Smokers & Ex-smokers \\
\hline Asthma & $\begin{array}{l}\text { Unadjusted } \\
\text { Adjusted for } \\
\text { pack years }\end{array}$ & $\begin{array}{l}0.79(0.49 \text { to } 1.27) \\
0.81(0.49 \text { to } 1.33)\end{array}$ & $\begin{array}{l}1.11(0.91 \text { to } 1.37) \\
1.06(0.86 \text { to } 1.32)\end{array}$ & $\begin{array}{l}1.63+(1.02 \text { to } 2.59) \\
1.59+(0.99 \text { to } 2.54)\end{array}$ & $\begin{array}{l}1.27(0.95 \text { to } 1.69) \\
1.19(0.88 \text { to } 1.60)\end{array}$ \\
\hline Bronchitis/emphysema & $\begin{array}{l}\text { Unadjusted } \\
\text { Adjusted for } \\
\text { pack years }\end{array}$ & $\begin{array}{l}1.11(0.78 \text { to } 1.60) \\
0.96(0.66 \text { to } 1.39)\end{array}$ & $\begin{array}{l}1.29 \S(1.07 \text { to } 1.55) \\
1.12(0.92 \text { to } 1.36)\end{array}$ & $\begin{array}{l}1.79-(1.25 \text { to } 2.56) \\
1.55 \ddagger(1.08 \text { to } 2.24)\end{array}$ & $\begin{array}{l}1.40 \ddagger(1.05 \text { to } 1.85) \\
1.22(0.92 \text { to } 1.63)\end{array}$ \\
\hline "Any OAD" & $\begin{array}{l}\text { Unadjusted } \\
\text { Adjusted for } \\
\text { pack years }\end{array}$ & $\begin{array}{l}1.14(0.83 \text { to } 1.55) \\
0.99(0.72 \text { to } 1.37)\end{array}$ & $\begin{array}{l}1.20 \mp(1.03 \text { to } 1.40) \\
1.08(0.92 \text { to } 1.27)\end{array}$ & $\begin{array}{l}1.72 \\
1.54 \mp(1.24 \text { to } 2.38)\end{array}$ & $\begin{array}{l}1.34 \pm(1.07 \text { to } 1.57) \\
1.24(0.98 \text { to } 1.56)\end{array}$ \\
\hline
\end{tabular}

Data are shown as odds ratios (with $95 \% \mathrm{CI}$ ) for childhood smokers relative to those who started to smoke in adulthood within each smoking category. $\uparrow \mathrm{p} \leqslant 0.05 ; \mathrm{p} \leqslant 0.02 ; \S \mathrm{p} \leqslant 0.008 ; \mathrm{q} \leqslant 0.001$. 


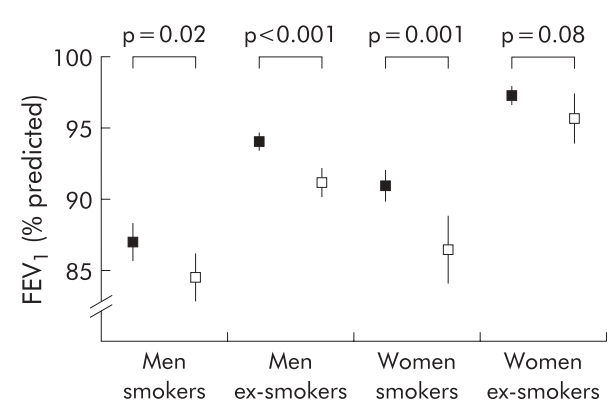

Figure 2 Mean $\mathrm{FEV}_{1}$ percentage predicted in male and female current and ex-smokers by age of starting smoking. Closed squares = started smoking in adulthood, open squares = started smoking in childhood. Vertical bars show $95 \% \mathrm{Cl}$.

difference in percentage predicted $\mathrm{FEV}_{1}$ in male current smokers and male and female ex-smokers. However, even after adjustment for pack years smoked, the percentage predicted $\mathrm{FEV}_{\mathrm{l}}$ remained significantly lower in female current smokers who started smoking in childhood (adjusted $\mathrm{FEV}_{1}$ 92.3\% predicted in adult smokers and $89.5 \%$ in childhood smokers, $\mathrm{p}=0.03$ ).

\section{DISCUSSION}

The prevalence of smoking in children age 13-15 years is as high as $40 \%$ in some countries. ${ }^{20}$ Our results show that, in addition to being more likely to continue smoking, childhood smokers have a greater risk of OAD and a lower $\mathrm{FEV}_{1}$ in adult life than those who start smoking in adulthood. In male and female ex-smokers the excess risk of lung disease is explained by the greater number of pack years smoked. In women who continue to smoke the increased risk of airways disease and reduction in $\mathrm{FEV}_{1}$ associated with childhood smoking is in addition to the increased number of pack years. Exposure to cigarette smoke during childhood is itself therefore an independent risk factor for the development of airways disease in these women.

It has been suggested that women who smoke may be at greater risk of developing COPD than men, ${ }^{21}$ and studies in adults suggest that women may be more susceptible to the effects of both active and passive smoking. Differences between men and women in the effects of smoking on pulmonary function and respiratory symptoms have also been described in young smokers. ${ }^{14} 1822$ In a recent longitudinal study the adverse effects of smoking on rate of lung growth were significantly greater in young female smokers than in male smokers. Moreover, whereas non-smoking females had a plateau in the $\mathrm{FEV}_{1}$ at age 16-17, female smokers showed a decline in $\mathrm{FEV}_{1}$ at this age. ${ }^{15}$ Our findings suggest that these effects of early life smoking persist into adult life in women who continue to smoke, and may contribute to an increased risk of COPD in female smokers.

The fact that we did not see this effect in women who were ex-smokers may be due to a number of factors. Ex-smokers are a heterogeneous group who may have stopped smoking for a variety of reasons-including social, cultural and health factors such as the onset of respiratory symptoms. Moreover, smoking cessation in early to mid life may be associated with some recovery in lung function, suggesting compensation for the excess loss in $\mathrm{FEV}_{1}$ that occurred during the period of smoking. ${ }^{23}{ }^{24}$

The normal development of lung function in childhood and adult life has been described in a number of studies. ${ }^{17} 232526$ In healthy non-smokers the $\mathrm{FEV}_{1}$ increases during childhood and early adult life. This is followed by a plateau phase after which there is a decline with increasing age. ${ }^{23}{ }^{25-27}$ The finding that childhood smoking is an independent risk factor for
OAD in women but not in men could be explained by differences in lung development between the sexes. Women reach their maximum $\mathrm{FEV}_{1}$ at an earlier age ${ }^{28}$ and have a shorter plateau phase than men and an earlier onset of decline in $\mathrm{FEV}_{1}{ }^{25}{ }^{27}$ In this analysis we defined childhood smokers as individuals who started smoking before the age of 16 years. However, the stage of lung maturation at this age differs between the sexes. In females it corresponds to the start of the plateau phase while in males the lung volume continues to increase into the third decade of life. ${ }^{28}$ In stratifying male smokers by age 16 years we may therefore have missed an independent effect of early life smoking. We have subsequently repeated the analysis comparing men who started to smoke before and after age 25 . This analysis did not show an independent effect of smoking below this age. However, as less than $4 \%$ of men in this cohort started smoking after the age of 25, the analysis may have had inadequate power to detect a significant effect.

The prevalence of doctor diagnosed chronic bronchitis/ emphysema was lower in male smokers $(10.8 \%)$ than in female smokers $(14.7 \%)$. Although this raises the possibility of diagnostic bias, it could reflect a higher prevalence of respiratory symptoms in female than in male smokers as has been previously reported..$^{29}$ An alternative explanation for this finding would be an over-representation of healthy smokers among men in the EPIC-Norfolk cohort. This seems unlikely as there was no significant difference in the prevalence of asthma between male smokers $(6.3 \%)$ and female smokers $(7.9 \%)$. Moreover, $\mathrm{FEV}_{1}$ percent predicted was significantly lower in male smokers $(86.1 \%)$ than in female smokers $(90.3 \%, \mathrm{p} \leqslant 0.001)$.

The association between smoking and airways disease was better explained by cumulative pack years of smoking than by duration or number smoked per day. In assessing the risk of childhood smoking we adjusted for the major confounding factor-pack years smoked. Although we adjusted for social class, we were unable to adjust for occupational exposure to dust and fumes which have been associated with an increased decline in $\mathrm{FEV}_{1}$. $^{3031}$ However, the East Anglia region of the UK is not heavily industrialised and does not have a high prevalence of occupational lung disease. We were also unable to adjust for the effects of parental social class or for parental smoking which is itself a risk factor for smoking in childhood..$^{15}{ }^{17}{ }^{32}$ Moreover, early life exposure to environmental tobacco smoke has been associated with reduced pulmonary function. However, the effect of this is small. ${ }^{17}{ }^{33}$ Data were also unavailable on childhood respiratory tract infections which may be associated with an increased risk of adult obstructive airways disease. ${ }^{34}$

The results of this study give considerable cause for concern as smoking remains prevalent among school children in many societies. Government spending in the UK on the prevention of smoking in young people constitutes a small fraction of the estimated revenue generated from childhood smoking and is tiny in relation to expenditure by tobacco companies on promotional campaigns. ${ }^{35}$ Our findings suggest that there should be a greater focus of public health policy on addressing smoking in school children. For example, although several surveys have found that most young smokers wish to stop, ${ }^{320}{ }^{32}$ there has been little research into the efficacy of cessation strategies in this age group. ${ }^{36}{ }^{37}$ It has been suggested that it is inefficient to focus limited resources on tackling smoking in children since they constitute only a small percentage of all smokers. ${ }^{38}$ The results presented here are at odds with this view. Children who smoke are more likely to become persistent adult smokers and, either because of their greater cumulative tobacco consumption or the effects of smoking on lung development, are at greater risk of developing OAD. 


\section{Authors' affiliations}

B D Patel, R N Luben, A A Welch, K-T Khaw, N E Day, N J Wareham, Department of Public Health and Primary Care, Institute of Public Health, Cambridge CB2 2SR, UK

S A Bingham, Dunn Human Nutrition Unit, University of Cambridge, Cambridge Institute for Medical Research, Cambridge CB2 2XY, UK

D A Lomas, The Respiratory Medicine Unit, University of Cambridge, Cambridge Institute for Medical Research, Cambridge CB2 2XY, UK

Bipen Patel is funded by a grant from the NHS Executive Anglia and Oxford R\&D

EPIC-Norfolk is supported by grant funding from the Cancer Research Campaign, the Medical Research Council, the Stroke Association, the British Heart Foundation, the Department of Health, the Europe Against Cancer Programme Commission of the European Union, and the Ministry of Agriculture, Fisheries and Food.

\section{REFERENCES}

1 Department of Health. Statistics on smoking: England 1978 onwards. Stat Bull 2000;17:1-36.

2 Nelson DE, Giovino GA, Shopland DR, et al. Trends in cigarette smoking among US adolescents, 1974 through 1991. Am J Public Health 1995:85:34-40.

3 Chabrol H, Faury R, Callahan S. French adolescent smoking and perception of quitting. J'Am Acad Child Adolesc Psychiatry 1999;38:640-1.

4 Department of Health and Human Services. Women and smoking. A Report of the Surgeon General. London: Department of Health, 2001.

5 Fletcher C, Peto R. The natural history of chronic airflow obstruction. BMJ 1977;1:1645-8.

6 Burrows B, Knudson RJ, Camilli AE, et al. The "horse-racing effect" and predicting decline in forced expiratory volume in one second from screening spirometry. Am Rev Respir Dis 1987:135:788-93.

7 Dockery DW, Speizer FE, Ferris BG Jr, et al. Cumulative and reversible effects of lifetime smoking on simple tests of lung function in adults. Am Rev Respir Dis 1988; 137:286-92.

8 Elders MJ, Perry CL, Eriksen MP, et al. The report of the Surgeon General: preventing tobacco use among young people. Am J Public Health 1994;84:543-7.

9 McNeill AD. The development of dependence on smoking in children. BrJ Addict 1991:86:589-92.

10 Wechsler H, Rigotti NA, Gledhill-Hoyt J, et al. Increased levels of cigarette use among college students: a cause for national concern. JAMA 1998;280(19): 1673-8.

11 Breslau N, Peterson EL. Smoking cessation in young adults: age at initiation of cigarette smoking and other suspected influences. Am J Public Health $1996 ; 86: 214-20$

12 Hymowitz N, Cummings KM, Hyland A, et al. Predictors of smoking cessation in a cohort of adult smokers followed for five years. Tob Control 1997;6(Supp 2):S57-62.

13 Morabia A, Costanza MC, Bernstein MS, et al. Ages at initiation of cigarette smoking and quit attempts among women: a generation effect. Am J Public Health 2002;92:71-4.

14 Enjeti S, Hazelwood B, Permutt S, et al. Pulmonary function in young smokers: male-female differences. Am Rev Respir Dis 1978;118:667-76.

15 Gold DR, Wang X, Wypii D, et al. Effects of cigarette smoking on lung function in adolescent boys and girls. N Engl J Med 1996;335:931-7.
16 Tager IB, Munoz A, Rosner B, et al. Effect of cigarette smoking on the pulmonary function of children and adolescents. Am Rev Respir Dis 1985;131:752-9

17 Lebowitz MD, Holberg CJ, Knudson RJ, et al. Longitudinal study of pulmonary function development in childhood, adolescence, and early adulthood. Development of pulmonary function. Am Rev Respir Dis 1987;136:69-75.

18 Neukirch F, Liard R, Cooreman J, et al. Prevalence of respiratory symptoms in Parisian teenagers according to smoking habits. J Epidemiol Community Health 1982;36:202-4.

19 Day N, Oakes S, Luben R, et al. EPIC-Norfolk: study design and characteristics of the cohort. European Prospective Investigation of Cancer. Br J Cancer 1999;80(Suppl 1):95-103

20 Global Youth Tobacco Survey. Tobacco use among youth: a cross country comparison. Tob Control 2002;11:252-70.

21 Pope M, Ashley MJ, Ferrence R. The carcinogenic and toxic effects of tobacco smoke: are women particularly susceptible? J Gend Specif Med 1999;2:45-51

22 Beck GJ, Doyle CA, Schachter EN. Smoking and lung function. Am Rev Respir Dis 1981;123:149-55.

23 Camilli AE, Burrows B, Knudson RJ, et al. Longitudinal changes in forced expiratory volume in one second in adults. Effects of smoking and smoking cessation. Am Rev Respir Dis 1987; 135:794-9.

24 Sherrill DL, Holberg CJ, Enright PL, et al. Longitudinal analysis of the effects of smoking onset and cessation on pulmonary function. Am J Respir Crit Care Med 1994; 149:591-7.

25 Dockery DW, Ware JH, Ferris BG Jr, et al. Distribution of forced expiratory volume in one second and forced vital capacity in healthy, white, adult never smokers in six U.S. cities. Am Rev Respir Dis 1985;131:511-20.

26 Burrows B, Cline MG, Knudson RJ, et al. A descriptive analysis of the growth and decline of the FVC and FEV1. Chest 1983;83:717-24.

27 Knudson RJ, Slatin RC, Lebowitz MD, et al. The maximal expiratory flow volume curve. Normal standards, variability, and effects of age. Am Rev Respir Dis 1976;113:587-600.

28 Becklake MR, Kauffmann F. Gender differences in airway behaviour over the human life span. Thorax 1999;54:1119-38.

29 Xu X, Li B, Wang L. Gender difference in smoking effects on adult pulmonary function. Eur Respir J 1994;7:477-83.

30 Krzyzanowski M, Jedrychowski W, Wysocki M. Factors associated with the change in ventilatory function and the development of chronic obstructive pulmonary disease in a 13-year follow-up of the Cracow study. Risk of chronic obstructive pulmonary disease. Am Rev Respir Dis 1986;134:1011-9.

31 Jaakkola MS, Ernst $P$, Jaakkola JJ, et al. Effect of cigarefte smoking on evolution of ventilatory lung function in young adults: an eight year longitudinal study. Thorax 1991;46:907-13.

32 Moran A, Maguire N, Howell F. Smoking and quitting among Irish teenage males. Ir Med J 2000;93:272-3

33 Wang X, Wypii D, Gold DR, et al. A longitudinal study of the effects of parental smoking on pulmonary function in children 6-18 years. Am J Respir Crit Care Med 1994; 149:1420-5.

34 Burrows B, Knudson RJ, Lebowitz MD. The relationship of childhood respiratory illness to adult obstructive airway disease. Am Rev Respir Dis 1977:115:751-60.

35 Foulds J, Godfrey C. Counting the costs of children's smoking. BMJ 1995;311:1152-4.

36 McFee RB, Boykan R, Lasner $\mathrm{H}$, et al. Promoting adolescent smoking cessation is worth the effort. Arch Pediatr Adolesc Med 2001;155:419-20.

37 Hurt RD, Croghan GA, Beede SD, et al. Nicotine patch therapy in 101 adolescent smokers: efficacy, withdrawal symptom relief, and carbon monoxide and plasma cotinine levels. Arch Pediatr Adolesc Med 2000; 154:31-7.

38 Anon. Kicking the teenage habit. Lancet 1995;346:453. 